\title{
Hapalopus aymara a new species of tarantula from Bolivia (Araneae, Theraphosidae, Theraphosinae)
}

\author{
Cintya Perdomo, Alejandra Panzera \& Fernando Pérez-Miles
}

Sección Entomología, Facultad de Ciencias, Igua 4225, 11400 Montevideo, Uruguay. (myga@fcien.edu.uy)

\begin{abstract}
A new species of Hapalopus Ausserer, 1875 (Araneae, Theraphosidae, Theraphosinae) from Bolivia is described and illustrated, based in males and females.
\end{abstract}

KEYWORDS. Tarantulas, Taxonomy, Neotropical.

RESUMO. Hapalopus aymara nova espécie de caranguejeira da Bolívia (Araneae, Theraphosidae, Theraphosinae). Uma nova espécie de Hapalopus Ausserer, 1875 (Araneae, Theraphosidae, Theraphosinae) da Bolívia é descrita e ilustrada, baseada em machos e fêmeas.

PALAVRAS-CHAVE. Caranguejeiras, Taxonomia, Neotropical.

The Theraphosinae are the most speciouse subfamily of theraphosid spiders exclusively distributed in the Neotropical Region. They are characterized by the presence of an extended subtegulum, and keels in male palpal organ and the presence of urticating hairs of types I and/or III and/or IV (COOKE et al., 1972) on the dorsal surface of the abdomen (RAVEn, 1985; Pérez-Miles et al., 1996). More than 400 species were described in the subfamily but a high number of unknown species are expected to occur in Araneae as a whole (CoDDINGTON \& LEVI, 1991) and also in this taxa. Although the difficulties for systematic studies (Schiapelli \& Gerschman, 1979; VAlerio, 1980; Minch, 1989; RAVEn, 1990; Bertani, 2000) due mainly to their morphological homogeneity, recent scientific contributions improve the tools for species recognition and consequently for the discovery of new species.

The genus Hapalopus Ausserer, 1875 includes eight species (Platnick, 2007) described from Brazil, Colombia, French Guiana, Mexico and Venezuela, the majority of which described in the second half of twenty century. Fukushima et al. (2005) transferred Cyriocosmus butantan Pérez-Miles, 1998 and Metriopelma nigriventris (MelloLeitão, 1939) to Hapalopus and indicated the following synapomorphies to this genus: the ring-shaped keel on palpal organ, the presence of tibial apophysis with convergent branches and the presence of a spermathecal receptaculum having a membranous base. Hapalopus is also characterized by the following character combination: the apical region of the bulb subconical, bulbal keels inequal, digitiform apophysis of bulb absent, male palpal tibiae with retrolateral process, flexion of metatarsus I between tibial apophysis, femur IV without retrolateral scopula, absence of stridulatory setae and numerous labial cuspules (PÉrez-Miles et al., 1996). Studying a sample collected in Beni, Bolivia, we found some individuals that present these characteristics but did not fit with any of the known species. In this study these specimens are described as Hapalopus aymara new species.

\section{METHODS}

Abbreviations: AME, anterior median eyes; ALE, anterior lateral eyes; PME, posterior median eyes; PLE, posterior lateral eyes; OQ, ocular quadrangle (including lateral eyes); d, dorsal; p, prolateral; r, retrolateral; $v$, ventral; FCE-MY, Arachnological Collection of Facultad de Ciencias, Montevideo, Uruguay.

All measurements are expressed in millimetres. Coordinates into brackets are approximate (not taken by Global Positioning System). Numbers between parenthesis in the description, represent the mean and standard deviation of type series.

\section{Hapalopus aymara sp. nov. \\ (Figs. 1-9)}

Types. Holotype male (FCE-MY 734), BOLIVIA, Beni: Rurrenabaque (16 22 '56'S, 67\%30'85' 'W) without date, Paul Stevenz leg.; paratypes: 2 males (FCE-MY 735 and FCE-MY 0736) from same locality and one female (FCE-MY 737) born in laboratory in Germany, mother collected in the same locality by Paul Stevenz.

Etymology. Noun in apposition that refers to the name of the language and culture from an important region of Bolivia and Peru, the word means old language.

Diagnosis. Differs from Hapalopus formosus Ausserer, 1875, by the palpal bulb morphology by the absence of prolateral superior keel and 25\% narrower ringshaped keel; from $H$. aldanus West, 2000, by the absence of basoventral cluster of short inward curled megaspines on metatarsus I, by the $40 \%$ narrower keel on palpal bulb, and femur III not swollen. Differs from $H$. tripepii Dresco, 1984 by the absence of a dorsal process in the cheliceral basal segment. From H. butantan (Pérez-Miles, 1998 ) by the $75 \%$ shorter embolus and the absence of abdominal stripped pattern. From H. nigriventris (MelloLeitão, 1939), H. guianensis Caporiacco, 1954 and $H$. 
triseriatus Caporiacco, 1955 by the absence of abdominal spotted or stripped pattern. From $H$. nondescriptus MelloLeitão, 1926 by the different palpal organ morphology in which embolus is twice longer in this species.

Male (Figs. 1-6). Total length, not including chelicerae or spinnerets, 17.3 (15.95 \pm 1.58$)$. Carapace length, $8.50(8.20 \pm 0.36)$, width $7.20(6.80 \pm 0.40)$. Anterior eye row straight, posterior eye row slightly recurved. Eye sizes and interdistances: AME 0.26 (0.25 \pm 0.01$)$, ALE 0.44

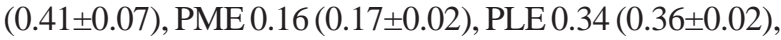
AME-AME 0.16 (0.14 \pm 0.02$)$, AME-ALE 0.06 (0.03 \pm 0.02$)$,

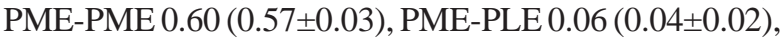
AME-PLE $0.11(0.08 \pm 0.04)$, OQ length $0.73(0.56 \pm 0.15)$, width $1.33(1.34 \pm 0.05)$, clypeus $0.15(0.17 \pm 0.02)$ high. Fovea transverse slightly procurved, width $0.50(0.80 \pm 0.26)$. Labium length $1.50(1.53 \pm 0.06)$, width $1.0(0.97 \pm 0.15)$ with $53(47 \pm 6)$ cuspules, maxillae with 140 (139 \pm 29$)$ cuspules. Sternum length $3.8(3.43 \pm 0.47)$. Chelicerae with 10 teeth on the promargin, small teeth on retromargin absent. Tarsi I-IV densely scopulated, scopula I undivided, II-IV divided by a narrow stripe of setae. Metatarsi I-IV scopulated on the apical quarter. Palpal tibia with a subapical spinose process on the retrolateral surface (Fig. 3). Tibia I with two distal proventral apophysis (Fig. 4). Flexion of metatarsus between tibial apophysis. Palpal organ piriform with a ring-shaped keel (Figs. 5, 6). Length of leg and palpal segments, in table I. Spination femora I-IV and palp 0. Patellae I-IV and palp 0. Tibia I 4v2p; II 5v3p; III 6v3p2r0d; IV 7v2p4r0d; palp 2v2p0r0d. Metatarsi I 2v1p1r; II 1v2p4r; III 3v5p1r1d; IV 2v5p3r0d. Tarsi I-IV and palp 0. Color: carapace, chelicerae coxae and trochanters light brown; abdomen and rest of palps and legs dark brown. Type III urticating hair present.

Female (Figs. 7-9). Total length, excluding chelicerae and spinnerets, 21.30. Carapace length 8.80. Width 7.10. Anterior eye row straight, posterior slightly recurved. Eyes sizes and interdistances: AME 0.20, ALE 0.35, PME 0.19, PLE 0.29, AME-AME 0.14, AME-ALE 0.09, PMEPME 0.73, PME-PLE 0.06, ALE-PLE 0.18, OQ length 0.69, width 1.41. Clypeus 0.1. Fovea transverse, width 1.1 . Labium length 1.90 , width 1.35 , with 49 cuspules, maxillae with 170 cuspules. Sternum length 3.85. Chelicerae with
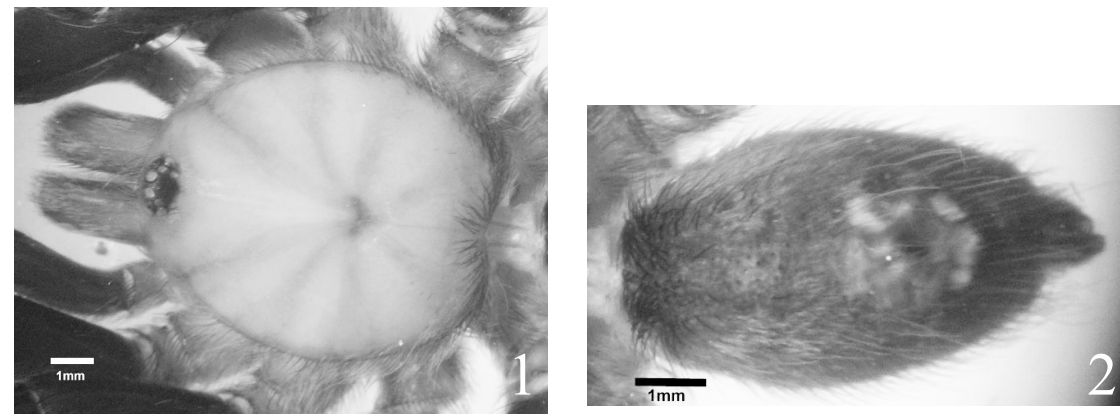

Figs. 1, 2. Hapalopus aymara sp. nov., male holotype, dorsal view: 1, carapace; 2, abdomen. Scales, $1 \mathrm{~mm}$
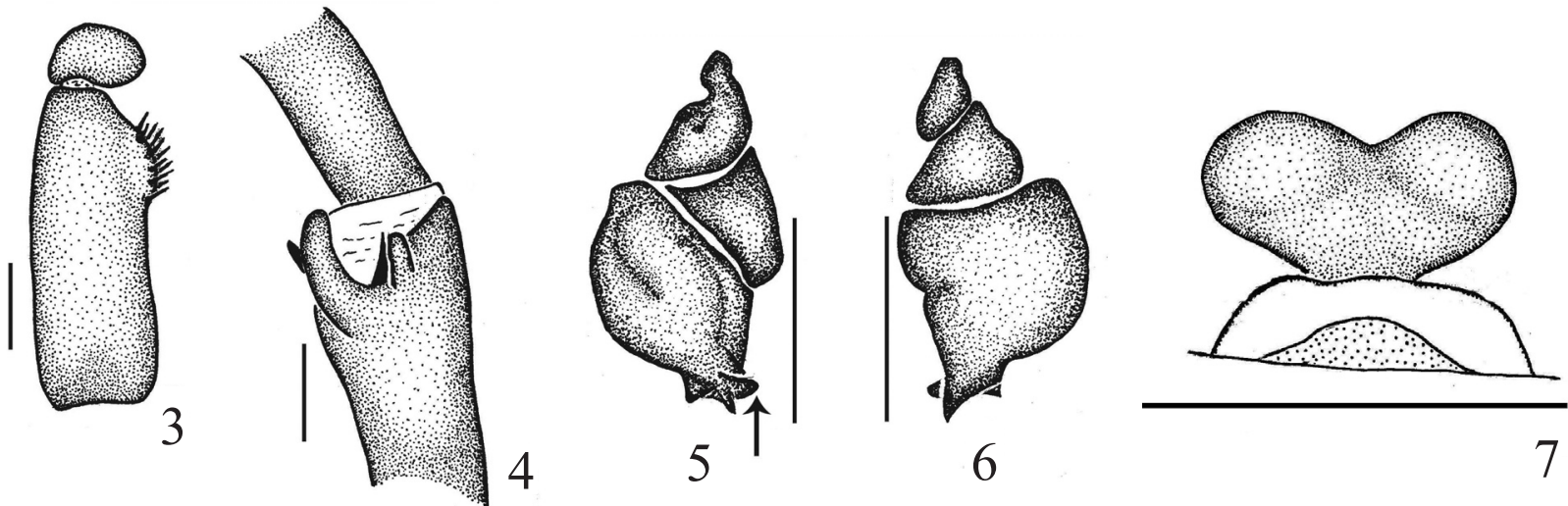

Figs. 3-7. Hapalopus aymara sp. nov.: 3, right palpal tibia showing the spinose retrolateral process, dorsal view; 4, right leg I with proventral tibial apophyses; 5, palpal organ, prolateral view (arrow shows the ring-shaped keel); 6, palpal organ, retrolateral view; 7 , espermathecae, ventral view. Scales, $1 \mathrm{~mm}$.
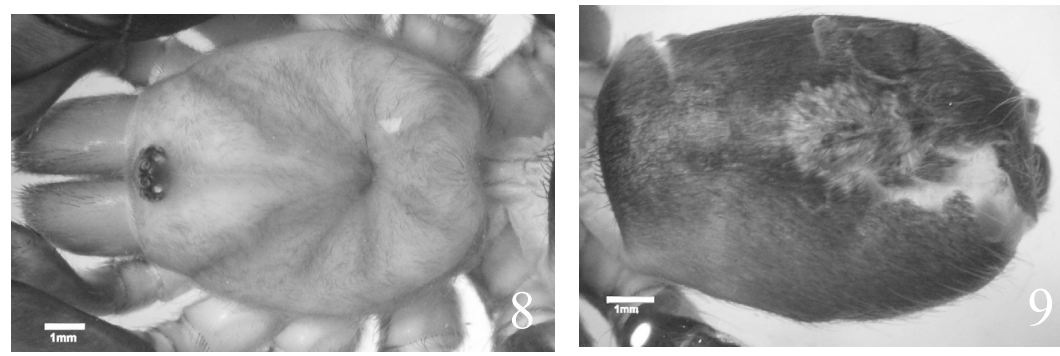

Figs. 8, 9. Hapalopus aymara sp. nov., female paratype, dorsal view: 8, carapace; 9, abdomen. Scale, $1 \mathrm{~mm}$. 
Table I. Hapalopus aymara sp. nov., male holotype, length of leg and palpal segments. Numbers in brackets represent the mean and standard deviation of male holotype and paratypes.

\begin{tabular}{lccccc}
\hline & I & II & III & IV & Palp \\
\hline Femur & $7.5(6.80 \pm 0.58)$ & $6.5(6.20 \pm 0.36)$ & $6.0(5.70 \pm 0.51)$ & $7.5(7.45 \pm 0.09)$ & $4.5(4.16 \pm 0.28)$ \\
Patella & $4.0(3.72 \pm 0.26)$ & $3.5(3.33 \pm 0.29)$ & $3.0(2.80 \pm 0.20)$ & $3.5(3.40 \pm 0.17)$ & $2.6(2.13 \pm 0.42)$ \\
Tibia & $5.8(5.40 \pm 0.46)$ & $4.5(4.13 \pm 0.32)$ & $4.0(3.80 \pm 0.20)$ & $6.5(5.90 \pm 0.66)$ & $3.8(3.53 \pm 0.15)$ \\
Metatarsus & $5.0(4.95 \pm 0.58)$ & $5.0(4.80 \pm 0.53)$ & $5.8(5.45 \pm 0.38)$ & $8.0(7.90 \pm 0.17)$ & \\
Tarsus & $3.7(3.25 \pm 0.80)$ & $3.7(3.08 \pm 0.68)$ & $3.7(3.15 \pm 0.74)$ & $4.5(4.13 \pm 0.47)$ & $1.3(1.47 \pm 0.15)$ \\
\hline
\end{tabular}

Table II. Hapalopus aymara sp. nov., female paratype, length of leg and palpal segments.

\begin{tabular}{|c|c|c|c|c|c|}
\hline & $\mathrm{I}$ & II & III & IV & Palp \\
\hline Femur & 6.3 & 5.0 & 5.0 & 7.0 & 4.0 \\
\hline Patella & 3.5 & 3.0 & 2.5 & 3.0 & 2.8 \\
\hline Tibia & 4.0 & 3.5 & 3.0 & 5.0 & 2.7 \\
\hline Metatarsus & 3.0 & 3.0 & 4.5 & 7.0 & \\
\hline Tarsus & 2.8 & 2.8 & 3.0 & 3.7 & 3.0 \\
\hline
\end{tabular}

10 teeth on the promargin, small teeth on retromargin absent. Tarsi I-IV densely scopulated, scopula I-IV divided. Metatarsi I and II scopulate on their apical third, III and IV scopulated on their apical quarter. Length of leg and palpal segments, in table II. Spination: femora I. 0v1 100rOd; II 0v1p0rOd; III-IV 0 and palp 0v1p0rOd. Patellae I-II 0; III 0v2p0r0d and IV 0v1p0r0d and palp 0. Tibiae I 0; II 4v0p0r0; III 4v3p2r0d; IV 4v1p2r0d; palp 4v0p0r0d. Metatarsi I 2v0p0r0d; II 4v0p0r0p; III 4v5p2r3d; IV 4v8p2r2d. Tarsi I-IV and palp 0. Spermathecae in a single heart-shaped receptaculum and a membranose base (Fig. 7). Color carapace, chelicerae coxae and trochanters light brown; abdomen and rest of palps and legs dark brown. Type III urticating hairs present.

Distribution. Only know from the type locality.

Acknowledgments. Mr. Dirk Weinmann (Deutsche Arachnologische Gesellschaft e.V.) who generously gave us the specimens used in this study. Dr. Rogerio Bertani (Instituto Butantan, São Paulo, Brazil) for his critical reading of the manuscript. Alexandre Bonaldo (Museu Paraense Emílio Goeldi, Pará, Brazil) and an anonymous reviewer for their useful comments.

\section{REFERENCES}

Bertani, R. 2000. Male palpal bulbs and homologous features in Theraphosinae (Araneae, Theraphosidae). The Journal of Arachnology 28:29-42.

Cooke, J. A. L.; Roth, V. D. \& Miller, F. H. 1972. The urticating hairs of theraphosid spiders. American Museum Novitates 2498: $1-43$.

Coddington, J. A. \& Levi, H. W. 1991. Systematics and evolution of spiders (Araneae). Annual Review of Ecology and Systematics 22:565-592.

Fukushima, C. S.; Bertani, R. \& da Silva Jr., P. I. 2005. Revision of Cyriocosmus Simon 1903, with notes on the genus Hapalopus Ausserer, 1875 (Araneae, Theraphosidae). Zootaxa 846:1-31.

Minch, E. W. 1989. Comments on the proposed presence of Aphonopelma Pocock, 1901 over Rechostica Simon, 1892 (Arachnida, Araneae). Bulletin of Zoological Nomenclature 46: 189 .

Pérez-Miles, F.; Lucas, S. M.; Silva JR., P. I. Da \& Bertani, R. 1996. Systematic revision and cladistic analisis of Theraphosinae (Araneae: Theraphosidae). Mygalomorph 1(3):33-68.

Platnick, N. I. 2007. The world spider catalog, version 7.5. American Museum of Natural History. Avaliable at: <http:// research.amnh.org/entomology/spiders/catalog/index.html>. Access on: 05.2007 .

RAVEn, R. J. 1985. The spider infraorder Mygalomorphae (Araneae): Cladistics and systematics. Bulletin of the American Museum of Natural History 182(1):1-180.

- 1990. Comments on the proposed presence of Aphonopelma Pocock, 1901 (Arachnida, Araneae) over Rhechostica Simon 1892. Bulletin of Zoological Nomenclature 47(2):126.

Schiapelli, R. D. \& Gerschman, B. S. P. 1979. Las arañas de la subfamilia "Theraphosinae" (Araneae, Theraphosidae). Revista del Museo Argentino de Ciencias Naturales "Bernardino Rivadavia" 5:287-330.

VALERIo, C. E. 1980. Arañas terafósidas de Costa Rica (Araneae, Theraphosidae). I. Sericopelma y Brachypelma. Brenesia 18:259-288

Recebido em julho de 2007. Aceito em setembro de 2008. ISSN 0073-4721 Artigo disponível em: www.scielo.br/isz 